\title{
Mujeres atrateñas, oficios reparadores y espacios de vida
}

\author{
Women from the Atrato River, Repair Practices and Living Spaces
}

\author{
Natalia Quiceno Toro*, Adriana Marcela Villamizar Gelves* \\ Instituto de Estudios Regionales de la Universidad de Antioquia, Colombia
}

DOI: $10.22380 / 2539472 X .702$

\begin{abstract}
RESUMEN
En el Chocó, los grupos Artesanías Guayacán (municipio de Bojayá) y Artesanías Choibá (municipio de Quibdó) congregan a mujeres negras alrededor de oficios textiles. En estos espacios propios las mujeres narran las experiencias vividas en medio del conflicto armado y crean conocimientos colectivos que les permiten rehacer la vida. En este artículo exponemos las formas en que las prácticas cotidianas agenciadas por estas mujeres atrateñas sostienen la vida en un río disputado por diversos actores políticos, económicos y armados. También mostramos de qué modo sus estrategias y luchas generaron procesos de subjetivación que cambian los lugares usualmente asignados a las mujeres en las comunidades y los procesos organizativos locales, redefiniendo los espacios públicos y domésticos.
\end{abstract}

Palabras claves: mujeres atrateñas, oficios textiles, conflicto armado, reparaciones.

\begin{abstract}
In Chocó, the groups Artesanías Guayacán (municipality of Bojayá) and Artesanías Choibá (municipality of Quibdó) gather black women around textile practices. In these spaces women tell their experiences amid the armed conflict and create collective knowledge that allows them to rebuild their lives. In this article we present the ways in which the daily practices of these women support life in a river disputed by various political, economic and armed actors. We also show how their strategies and struggles generated subjectivation processes that changed the places usually assigned to women in the communities and local organizational processes, redefining public and domestic spaces.
\end{abstract}

Keywords: women from the Atrato river, textile practices, armed conflict, reparations.

natalia.quiceno@udea.edu.co / https://orcid.org/0000-0001-9689-4835

*_ adriana.villamizar@udea.edu.co / https://orcid.org/0000-0002-4676-6189

1 Los aportes de la profesora Quiceno a este artículo se realizaron en el marco de la estancia de investigación financiada por el Centro Maria Sibylla Merian de Estudios Latinoamericanos Avanzados en Humanidades y Ciencias Sociales (Calas), habiendo participado en el Laboratorio de Conocimiento "Visiones de paz: transiciones entre violencia y paz en América Latina". 
No todo puede ser guerra, en medio de la guerra tiene que haber algo muy lindo que nosotras mismas valoremos, que lo sintamos nuestro, que sea nuestro y que no sea de la guerra, porque, aunque estemos dentro de ella, tenemos un espacio que no es de la guerra. Nosotras tenemos unas historias fuera de la guerra que son nuestras y que en medio de todo esto han permanecido y hoy compartimos. (Testimonio de mujer bojayaseña, junio del 2017)

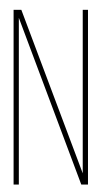

oviembre del 2018. Un telón grande, con más de 79 nombres bordados en telas de diversos colores, acompaña la visita de la Comisión de Paz de la Cámara de Representantes al municipio de Bojayá. Esta visita fue impulsada por el Foro Interétnico Solidaridad Chocó, la Mesa de Concertación de los Pueblos Indígenas y el Comité por los Derechos de las Víctimas de Bojayá, como parte de las acciones que denuncian los incumplimientos del Gobierno nacional con las víctimas y la crisis humanitaria $^{2}$ del departamento del Chocó, que demanda un acuerdo especial en el marco de los diálogos de paz con la guerrilla del Ejército de Liberación Nacional (ELN)33. El telón, elaborado en el 2003 para la conmemoración del primer año de la masacre de Bojayá ${ }^{4}$, reunió a mujeres de Bojayá y Quibdó, bordadoras expertas, en un gesto de silencio, trabajo y memoria que rinde homenaje a los caídos en aquel hecho. Como recuerda Macaria, una de las mujeres del grupo Guayacán, bordar fue una manera de "sentir que en cada puntada estaba haciendo algo por esos seres queridos muertos”. Si bien es una pieza (figura 1) que ha circulado por muchos lugares del país, e incluso fuera de Colombia, poco se sabe de las manos que lo elaboraron. De ellas trata este artículo.

Situación que amenaza la salud, bienestar y seguridad de una población. En el caso del Chocó, se hace especial énfasis en las situaciones de confinamiento y destierro ocasionadas por el accionar de diversos actores armados, sumadas a la fragilidad institucional y la ausencia de servicios básicos que garanticen el bienestar de la población y el ejercicio de sus derechos. ELN y hasta la fecha no se ha reanudado, lo cual ha tenido graves impactos en las dinámicas del conflicto armado en departamentos como Chocó, Arauca y Norte de Santander. 
Figura 1. Telón Nuestras víctimas, 2 de mayo del 2002, Bellavista-Bojayá-Chocó. Haciendo historia, bordando memoria

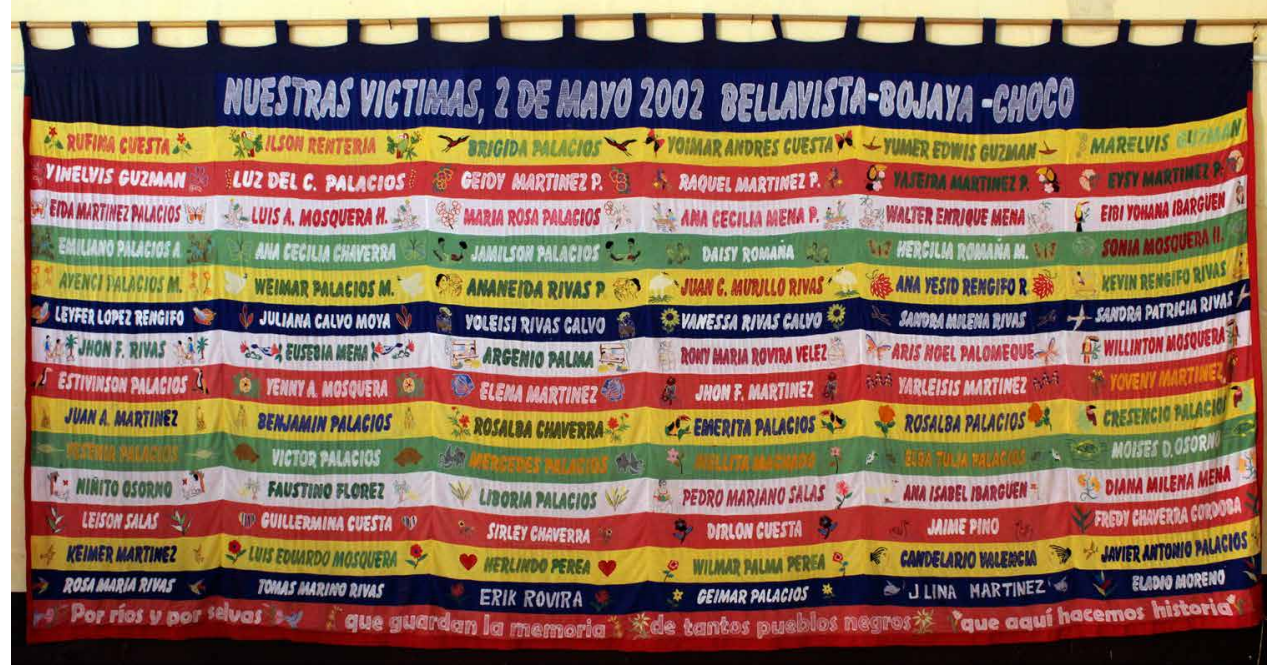

Fuente: fotografía de Adriana Villamizar, Bojayá, 2019.

Figura 2. Telón Nuestras víctimas, 2 de mayo del 2002, Bellavista-Bojayá-Chocó. Haciendo historia, bordando memoria, expuesto en la iglesia de Bellavista Viejo durante la decimosexta conmemoración de la masacre de Bojayá

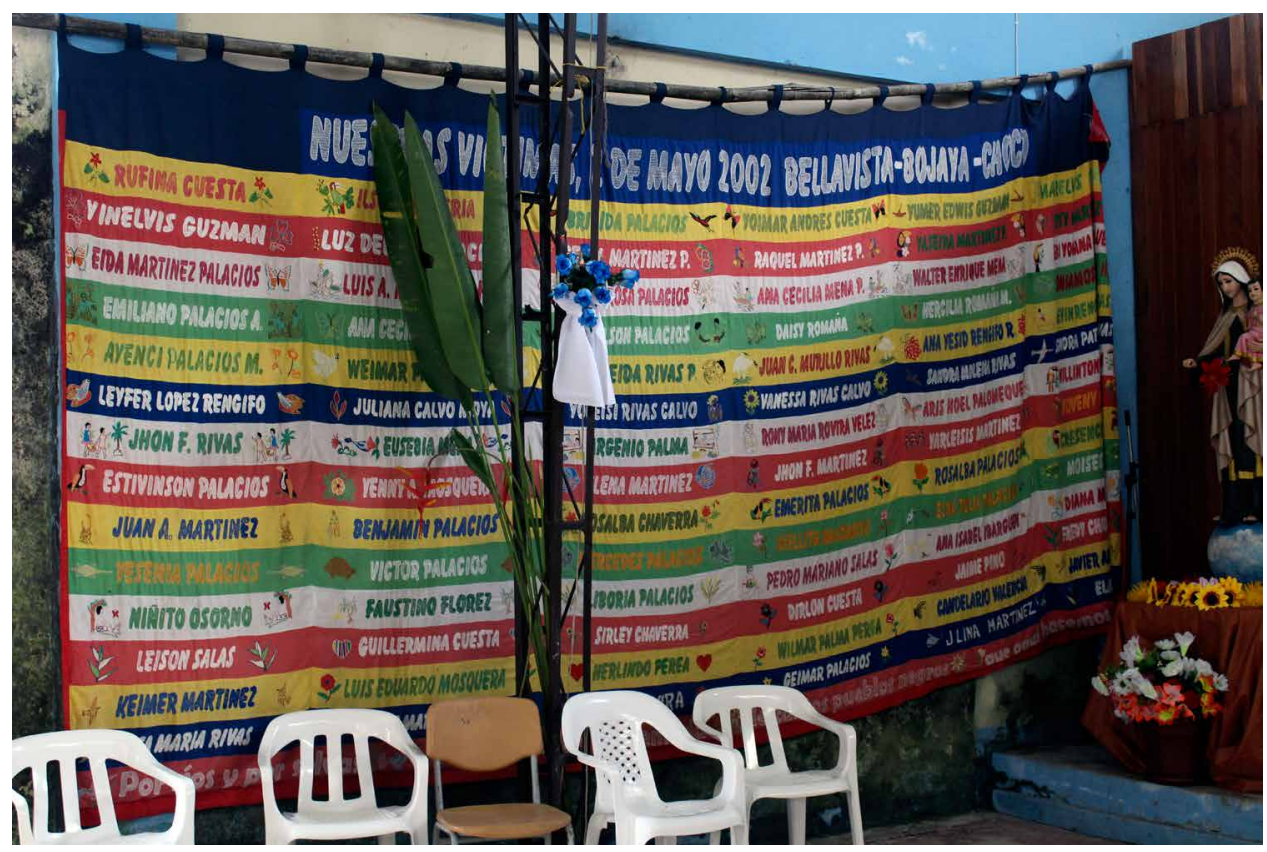

Fuente: fotografía de Adriana Villamizar, Bojayá, 2018. 
Otro telón tiene como centro al río Atrato, acompañado de un poema y del árbol de choibá. El telón (figuras 3 y 4) muestra pequeñas escenas de la vida cotidiana, objetos, alimentos, oficios, cuerpos de mujeres y hombres que hacen la vida en el día a día de la cuenca del Atrato; en estas escenas las personas están acompañadas por un árbol, el choibá, que le da el nombre a su grupo. Como dice una de las fundadoras, Luz Romaña, este árbol representa la fuerza (por la resistencia de su madera) y el duelo por lo que han perdido en medio de la guerra (en sus flores moradas). El telón está enmarcado por palabras bordadas con hilo blanco que dan cuenta de los valores, principios y proyectos del grupo Artesanías Choibá durante sus veinte años de trabajo.

Figuras 3 y 4. Detalles del telón 20 años de Artesanías Choibá
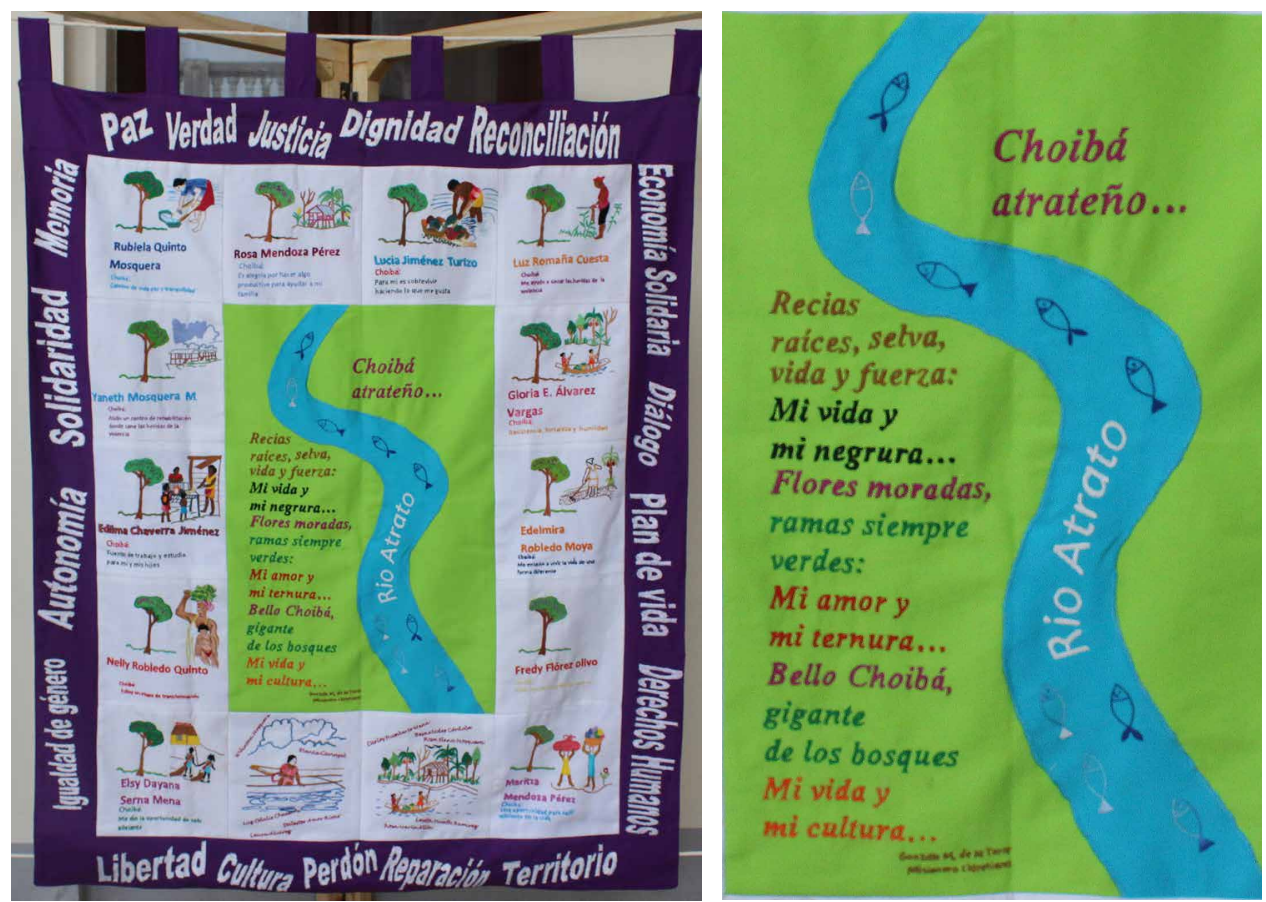

Fuente: fotografías de Natalia Quiceno y Adriana Villamizar, Quibdó, Chocó, 2018.

Los telones fueron elaborados por los grupos de Artesanías Guayacán, en el municipio de Bojayá, y Artesanías Choibá, en el municipio de Quibdó. En este artículo queremos mostrar de qué modo los oficios y los espacios de trabajo colectivo alrededor de la actividad artesanal y textil han contribuido a la recuperación de vidas afectadas por la guerra. Aquí nos interesamos por las micropolíticas del hacer cotidiano en las que bordar y tejer sostienen proyectos de resistencia creativa para hacer de los daños causados por la guerra algo diferente a una herida 
dolorosa o una fuente de rabia y venganza. Como lo plantea la socióloga Silvia Rivera Cusicanqui, la micropolítica trabaja "con colectivos pequeños y acciones corporales que permiten que florezcan espacios de libertad”, se trata de "articular el trabajo manual con el trabajo intelectual, producir pensamiento a partir de lo cotidiano” (en Barber 2019). Nos preguntamos entonces: ¿Qué nos enseñan esas manos bordadoras sobre el río Atrato y su historia reciente? ¿Cómo se crean espacio, conocimiento y resistencia en el hacer textil?

En este artículo retomamos la experiencia de dos colectivos ubicados en la cuenca del río Atrato en el departamento del Chocó: Artesanías Guayacán y Artesanías Choibá. Las reflexiones propuestas aquí retoman conversaciones y encuentros producidos en el marco de dos proyectos de investigación: "Caminos y cantos de lucha: trayectorias de mujeres bojayaseñas" $\mathrm{y}$ "Remendar lo nuevo: practicando reconciliaciones a través del quehacer textil y la memoria digital en la transición al postconflicto de la Colombia rural”6.

Ambos proyectos se realizaron desde una perspectiva etnográfica colaborativa y experimental (Estalella y Sánchez 2018). En el primer caso, a partir de talleres de elaboración de muñecas de trapo y bordado, construimos pequeñas historias de vida de las mujeres y los grupos. Esos espacios de conversación y aprendizaje nos permitieron reconocer los modos como los oficios textiles atravesaban su experiencia personal y ganaron protagonismo en situaciones de conflicto armado. En el segundo proyecto, la metodología se nutrió con diálogos interdisciplinares que permitieron experimentar desde las prácticas textiles y digitales conceptos como reconciliación, reparación y paz. Este proyecto aún se encuentra en desarrollo. A lo largo de este artículo utilizamos los nombres de las mujeres con su consentimiento, así como las imágenes de sus obras.

El Medio Atrato ha sido un territorio narrado desde las tensiones entre la guerra y las apuestas tanto estatales como comunitarias para la construcción de paz. A continuación expondremos las prácticas cotidianas agenciadas por las mujeres atrateñas para sostener la vida en un río disputado por diversos actores

$5 \quad$ Finalizado en el 2018 y financiado por el Comité para el Desarrollo de la Investigación de la Universidad de Antioquia (CODI). Este proyecto indagó sobre las luchas de mujeres negras en el Atrato, en las cuales experiencias vitales como el viaje, la crianza y el cuidado de extensas parentelas, la protección y el acompañamiento ritual, el canto y el fortalecimiento de redes de solidaridad que trascienden los espacios de residencia se convirtieron en asuntos claves para ampliar la comprensión de lo político.

6 Proyecto financiado por Colciencias y el Fondo Newton en la convocatoria Paz Sostenible en Colombia 2017. Busca comprender cómo se gestan reconciliaciones desde las prácticas textiles en varios colectivos de mujeres que han acudido a este oficio después de arduos procesos de victimización en el marco del conflicto armado colombiano. Para ampliar, véase: http:// artesanaltecnologica.org/remendar_lo_nuevo-2/ 
políticos, económicos y armados, y se reconocerán las formas en que sus luchas han generado procesos de subjetivación potentes que marcan cambios en los lugares, prácticas y roles sociales asignados a las mujeres dentro de las comunidades, los procesos organizativos locales y los espacios públicos y domésticos. Para ello nos inspiramos en los aportes de Michel de Certeau ([1990] 2000) sobre las artes de hacer cotidianas y su relación con la resistencia y el espacio, y en los trabajos de Silvia Rivera Cusicanqui (2018) sobre las micropolíticas del hacer cotidiano y de Betty Ruth Lozano (2016) alrededor de la insurgencia de saberes.

Como destaca Lozano (2014), las mujeres negras han configurado y mantenido su liderazgo a través de diversas prácticas, como la religión, la medicina, los cantos, los ritos mortuorios, así como mediante la relación con las plantas y el cuidado de los cultivos, espacios imprescindibles para comprender las nociones propias de política y bienestar que se configuran en las sociabilidades femeninas dentro de las comunidades negras rurales. Esta autora, al igual que los feminismos afrodiaspóricos (Vergara-Figueroa y Arboleda 2014), articula las luchas de las mujeres negras a los procesos colectivos de las luchas antirracistas y las luchas por la autonomía territorial en el Pacífico colombiano (Lozano 2014, 348). Aquí veremos cómo esa insurgencia de saberes (Lozano 2014) opera en mujeres que son víctimas del conflicto armado y de diversas modalidades de despojo en la región. A su vez, nos proponemos mostrar de qué modo las mujeres rurales que hoy habitan centros poblados o ciudades como Quibdó actualizan esos saberes y los conectan con nuevos oficios, en este caso textiles, para reconstruir sus vidas y hacer memoria.

Como lo plantean Bello y Aranguren (2020), se trata de espacios donde "se movilizan afectos y se cuida del otro" (189). Son espacios creados por las mujeres donde se comparten experiencias de movilidad, destierro y reparación cotidiana (Balduino de Melo 2015). Estos oficios y espacios están articulados, en algunos casos, por los conocimientos que las mujeres adquirieron desde su infancia y su socialización como mujeres y, en otros casos, por conocimientos compartidos en medio de las crisis como alternativas para sanar heridas, hacer duelos, ocupar la mente y buscar modos de subsistencia. En este sentido, entendemos estos oficios textiles como conocimiento y al tejido, como conocimiento incorporado, esto es, conocimientos que son con el cuerpo (Pérez-Bustos 2016, 168). En los casos veremos cómo ese sentido incorporado adquiere una dimensión colectiva en tanto el espacio de trabajo y la posibilidad del encuentro para bordar y tejer se dan siempre en relación con otras mujeres.

El artículo se desarrolla en tres partes. La primera ubica a la región y contextualiza las experiencias de algunas de las mujeres con quienes trabajamos en medio de las disputas y los conflictos. La segunda propone un acercamiento a los 
colectivos de mujeres y los espacios desde donde reconstruyen sus vidas después de experiencias como el destierro, las masacres o las diversas violencias en la ciudad. La tercera retoma esas insurgencias de saberes donde el hacer textil, bordar y tejer, configura formas de defensa y cuidado de la vida en contextos donde la militarización y la muerte se han consolidado como forma de gobierno.

\section{El Atrato: un río en disputa ${ }^{7}$}

Desde los Farallones del Citará, en la cordillera Occidental, hasta su desembocadura en el golfo de Urabá, el río Atrato forma parte de los departamentos de Antioquia y Chocó, dando vida a once municipios. Desde antes de la Colonia este territorio estaba habitado por comunidades indígenas, no obstante, su dinámica de poblamiento cambió cuando la comercialización de personas esclavizadas, traídas de África por los españoles para el trabajo minero, se propagó hacia el Caribe y el Pacífico colombiano y, como respuesta al régimen colonial, grupos de negros e indígenas se declararon en resistencia y formaron poblados independientes a lo largo de los afluentes en los que trabajaban (Burgos 2010). Por eso, la región está mayoritariamente poblada por afrodescendientes y en menor medida por grupos indígenas. A lo largo de estos siglos muchas historias han corrido por las aguas atrateñas. Misiones religiosas, rutas para la extracción de minerales ${ }^{8}$ y exploraciones botánicas han constituido este río como un universo social, económico y cultural de singular importancia. Sin embargo, solo hasta la segunda mitad del siglo pasado el afluente comenzó a resonar con mayor protagonismo en los titulares de la historia nacional, ya que, al pertenecer a la región pacífica y ser reconocido como una zona con gran potencialidad para la explotación de recursos naturales, el río es uno de los principales escenarios geoestratégicos para el desarrollo económico del país.

Así, particularmente desde la década de 1970, al Atrato han llegado diferentes actores armados y no armados como insurgencias, empresas con proyectos agroindustriales y comerciales, grupos paramilitares, miembros de la fuerza pública y grupos delincuenciales con la intención de controlar ese espacio y las

7 Para una ampliación detallada de las dinámicas del conflicto en la región del Atrato, véase Villamizar (2019).

8 Desde la Colonia, el Atrato ha sido una importante vía de comunicación y comercio entre el interior del país y el Caribe. Por sus aguas se transportaron gente, metales, maderas, productos no maderables del bosque, pieles, fauna silvestre, entre otros. 
vidas que se dan en él. En ese sentido, la historia reciente del Atrato es una expresión regional de los enfrentamientos enmarcados en el conflicto armado colombiano que comenzó a mediados del siglo XX alrededor de los problemas agrarios. Cerca de cuarenta años de conflicto produjeron la confluencia de asesinatos, desplazamientos forzados, despojo de tierras, masacres y desapariciones forzadas, hechos que han dejado miles de víctimas de la población civil.

Sobre el conflicto armado en la región varios estudios coinciden en analizar las múltiples disputas por el río en el marco de la llegada de los actores armados al territorio (Agudelo 2001; Defensoría Delegada para la Prevención de Riesgos de Violaciones a los Derechos Humanos y DIH 2016; Holzapfel y Kollwitz 2014). Es posible identificar tres fases de esas disputas: la primera, de la década de los 1970 a 1995, protagonizada por la llegada de las insurgencias, especialmente de las antiguas Fuerzas Armadas Revolucionarias de Colombia-Ejército del Pueblo (FARC-EP); la segunda, de 1996 hasta el 2004, producto de la avanzada de los grupos paramilitares del Bloque Élmer Cárdenas provenientes del Urabá antioqueño; y la tercera, desde el 2005 hasta el presente, asociada con la ocupación de grupos paramilitares posdesmovilización y bandas criminales. A esta última se suman las dinámicas conflictivas que se reconfiguran después de la firma del acuerdo de paz con las FARC-EP en el 2016, en las que coexisten las políticas derivadas del acuerdo para implementar la paz y el recrudecimiento de la confrontación armada entre actores que buscan copar zonas estratégicas para las economías ilegales.

Ahora, la forma como aparecen estos conflictos en las memorias de las mujeres atrateñas depende de lo que cada una de ellas haya vivido frente a la multiplicidad de situaciones, actores y experiencias violentas -en principio relacionadas con la guerra-, que rompieron la cotidianidad de sus casas, sus pueblos y su río. Así, por ejemplo, aunque la llegada de los actores insurgentes ocurre desde los años 1970, los últimos años de la década de 1980 y los primeros de la década de 1990 son los que determinan un cambio sustancial en las vidas de las mujeres de Artesanías Guayacán del municipio de Bojayá en el Medio Atrato, pues la amenaza de los grupos paramilitares en sus territorios por las posibles confrontaciones con las insurgencias fue lo que las motivó a reunirse alrededor de la oración y del bordado que luego daría vida al grupo de artesanas. Como lo describe Elizabeth Álvarez, con la presencia de los grupos paramilitares toda la vida, la cotidianidad en el río cambia:

Y entonces ya, pues, todo eso generó temor, miedo, porque ya empezaron ellos [los paramilitares], por ejemplo, a ejercer dominio en el territorio, pero también a matar de manera selectiva, entonces iban matando individual, que otro, que no sé qué, y entonces todas esas cosas empezaron 
a desencadenar miedos en la comunidad y en los grupos organizados, porque de igual manera como se dio acá en Bellavista, también se dio en las comunidades rurales. (Elizabeth Álvarez, comunicación personal, junio del 2017)

La llegada de los paramilitares a la región no fue fortuita. Hacia finales de los años 1980 y los 1990, en el plano nacional e internacional se propusieron varios proyectos económicos estratégicos para la región del Pacífico, sobre todo, el incremento de las actividades extractivas madereras y mineras, y la búsqueda de sustitutos del petróleo mediante cultivos agroindustriales como la palma de aceite que llegaron con fuerza a instalarse en la cuenca atrateña y desembocaron en una nueva disputa territorial. Con los nuevos actores económicos, además de nuevas dinámicas productivas, se incrementó la presencia del Ejército Nacional y de los grupos paramilitares del Bloque Élmer Cárdenas de las Autodefensas Unidas de Colombia (AUC) desde el Urabá antioqueño, quienes, con el discurso sobre "la necesidad de expulsar a las insurgencias del territorio atrateño", terminaron amenazando, estigmatizando, persiguiendo y asesinando a la población civil.

En el marco de estas acciones “en contra de la guerrilla”, entre 1996 y 1997 tuvieron lugar la Operación Génesis (ejecutada por el Ejército) y la Operación Cacarica (realizada por los paramilitares). Años después, estas acciones se revelarían concertadas y como los principales desencadenantes del desplazamiento forzado y el despojo de tierras de las comunidades, con el objeto de abrir camino a la economía agroindustrial. Lo mismo sucedió en Jiguamiandó y Curvaradó (Bajo Atrato), donde los paramilitares expulsaron a casi toda la población y, luego, empresas como la Unión de Cultivadores de Palma de Aceite en el Urabá (Urapalma S. A.) sembraron grandes extensiones de cultivos de palma aceitera (Romero 2010).

La presencia paramilitar definió un periodo signado por la crisis humanitaria y graves violaciones a los derechos humanos de los atrateños. Los registros de personas desplazadas que arribaban desde el Bajo y Medio Atrato a Quibdó y otras capitales del país empezaron en 1997 y se incrementaron en los años siguientes. Este aumento del desplazamiento forzado marcó las memorias de las mujeres del grupo Artesanías Choibá frente a sus vivencias de guerra, pues las familias que no encontraban refugio en Quibdó decidieron tomarse el Coliseo Municipal de la ciudad para exigir sus derechos y asentarse allí mientras se resolvía su situación. Este fue el lugar donde se encontraron las mujeres que luego crearían el grupo de artesanías. Luz Romaña, una de las fundadoras, recuerda que fue en el coliseo donde, junto a Úrsula Holzapfel, aprendieron a hacer las primeras muñecas que inspiraron la idea de conformar un proyecto 
productivo alrededor de productos bordados y tejidos que les permitiera, como mujeres, emplearse en algo en una ciudad que no les ofrecía ninguna oportunidad laboral, salvo trabajar como empleadas domésticas con un ingreso precario:

Úrsula fue la que nos llevó eso, cuando estábamos en el coliseo que empezamos a hacer las muñecas, y esas muñecas empezaron por el desplazamiento para una Navidad en la que no teníamos regalo para darle a sus hijos, entonces ella dijo que si queríamos hacer unas muñecas para hacerle el regalo a nuestros hijos, le dijimos que sí, y ya empezamos a hacer las muñecas. (Luz Romaña, comunicación personal, junio del 2017)

El trabajo desarrollado en el coliseo, donde se realizaba otra serie de actividades simultáneas para proteger a la población desplazada y demandar justicia, permitió crear un espacio de escucha y organización. Al final de los años 1990 los desplazamientos forzados masivos ocurrieron a la par de asesinatos, desapariciones forzadas y enfrentamientos armados. Uno de los hechos más graves y renombrados fue la masacre de Bojayá, ocurrida en la cabecera municipal conocida como Bellavista, el 2 de mayo del 2002, hecho trágico que dejó más de noventa personas muertas a causa de la explosión de una pipeta bomba en la iglesia donde se refugiaba la población civil por un enfrentamiento entre las FARC-EP y los paramilitares.

La disputa entre insurgencias, paramilitares y Ejército tomó un nuevo rumbo a partir del 2005, cuando las AUC iniciaron su desmovilización después de un proceso de negociación con el gobierno de Álvaro Uribe. No obstante, en muchos lugares la salida de los paramilitares no se efectuó de manera completa; algunos cambiaron de nombre y continuaron su accionar bélico. Por tanto, en el Atrato los años posteriores a esa desmovilización han representado la ocupación del territorio por grupos armados de difícil caracterización, como las Autodefensas Gaitanistas de Colombia (AGC), los Urabeños y el Clan del Golfo. La Diócesis de Quibdó reconoce a estos grupos como parte de las estructuras paramilitares posdesmovilización (Defensoría Delegada para la Prevención de Riesgos de Violaciones a los Derechos Humanos y DIH 2016). Por su parte, las instituciones estatales se refieren a estos grupos como bandas delincuenciales que buscan controlar la cuenca para actividades como el contrabando y el narcotráfico. De cualquier manera, estos grupos se han integrado a los ciclos de violencia y amenaza hacia las comunidades atrateñas, aun cuando tanto las insurgencias de las FARC-EP y el ELN, como los nuevos actores económicos, se encontraban en la cuenca del Atrato (Defensoría Delegada para la Prevención de Riesgos de Violaciones a los Derechos Humanos y DIH 2016, 57). 
La permanencia de las disputas entre actores armados por el afluente se expresa desde el 2005 como un reordenamiento de fuerzas diversas en los poblados ribereños. La particularidad de la nueva disposición de estructuras de poder se ha caracterizado por el control delincuencial de la ciudad de Quibdó, que ha devenido en una violencia urbana sin precedentes de la que los jóvenes y las mujeres son los principales afectados. Cabe advertir que esta violencia la sufre sobre todo la población desplazada. Según el Registro Único de Víctimas, en esta ciudad hay 68.766 víctimas, aproximadamente el $63 \%$ del total de los habitantes de Quibdó (Red Nacional de Información 2018). Dentro de este porcentaje se encuentran las mujeres de Artesanías Choibá, quienes en su mayoría viven en barrios de la zona norte donde se edificaron los primeros asentamientos de familias desplazadas y actualmente las bandas criminales tienen mayor presencia.

En medio de estas disputas cabe destacar los cambios influenciados por la multiplicidad de procesos de negociación y propuestas de salida pacífica a los conflictos entre actores armados de los últimos años. En el 2012 las FARC-EP y el gobierno de Juan Manuel Santos iniciaron conversaciones para negociar el cese de su conflicto. El 24 de noviembre del 2016 ambos bandos firmaron el Acuerdo Final para la Terminación del Conflicto y la Construcción de una Paz Estable y Duradera. Este hito marcó un nuevo ordenamiento entre las fuerzas que ocupan el río Atrato, sobre todo porque el Gobierno ha fallado en el seguimiento y la implementación de los puntos pactados, situación que ha generado una falta de presencia estatal en los lugares donde esta insurgencia ejercía control, y que están siendo ocupados y disputados por el ELN, los grupos paramilitares y los delincuenciales. En este sentido, la Alerta Temprana 011-18 emitida el 24 de enero del 2018 advirtió sobre los posibles enfrentamientos entre grupos de las AGC y el ELN que estaban asentándose en los municipios de Bojayá, Medio Atrato y Vigía del Fuerte (Defensoría del Pueblo 2018).

De igual manera, la frustrada mesa de negociación con la insurgencia del ELN y la debilidad de este proceso causaron una nueva crisis humanitaria en el río y, en general, en todo el departamento del Chocó. Para enfrentar y mitigar estas afectaciones, varias organizaciones comunitarias del Chocó redactaron en octubre del 2017 el Acuerdo Humanitario Ya para el Chocó, un documento con nueve exigencias al Gobierno y al ELN que demandan la continuidad del diálogo (“Con capítulo especial para Chocó arranca cese del fuego con el ELN" 2017), pero este aún no ha encontrado eco en el gobierno de Iván Duque, quien el 18 de enero del 2019 levantó la mesa de negociación e ignoró los llamados de la sociedad civil para mantenerla activa.

El reacomodamiento y la diversificación de fuerzas armadas en medio de los escenarios de negociación y transición, además de un clima de zozobra entre 
las comunidades, también ha intensificado la amenaza y el asesinato de líderes y lideresas sociales de las organizaciones que se oponen a la presencia de estos actores en sus territorios. Desde diciembre del 2016 hasta el 4 de julio del 2018 se registraron en la zona del Atrato nueve líderes asesinados ("El mapa de los líderes sociales asesinados en Colombia” 2018). Aun así, las organizaciones comunitarias han continuado sus procesos de defensa y reclamación territorial y las redes se han fortalecido con nuevos logros, como la declaración en el 2016 del río Atrato como sujeto de derechos mediante la Sentencia T-622 de la Corte Constitucional. Esta acción jurídica otorga a las comunidades una herramienta para la defensa de su territorio frente a las actividades mineras y agroindustriales que afectan la vida del río.

Las experiencias de las mujeres atrateñas en un río en disputa nos enseñan que es necesario preguntarse por los espacios, las materialidades y entidades que componen las luchas cotidianas y que hacen posibles nuevas vitalidades, aquellas que retan los "consensos” sobre la guerra, la política y la paz. En la coyuntura política que vive Colombia de cara a la construcción de la paz, es necesario reconocer los oficios, espacios y conocimientos que han sostenido la vida desde otras estéticas, ritualidades y otras comprensiones de lo político. Volver sobre la proliferación diseminada de creaciones anónimas y perecederas que hacen vivir y que no se capitalizan (Certeau 2000).

\section{Artesanías Choibá y Guayacán Choibá}

En la calle 31 de la agitada y calurosa ciudad de Quibdó, nos encontramos con Edelmira para tomar el colectivo y ser guiadas hasta el barrio Villa España, en la zona norte de Quibdó. Villa España fue fundado en el 2000 para dar acogida a cientos de familias desplazadas que exigían atención del Estado mientras habitaban temporalmente el coliseo de la ciudad donde habían encontrado refugio después de ser desterradas de sus fincas y parcelas en la cuenca del Atrato a finales de los años 1990. Al llegar, la imagen de un barrio con viviendas de interés social se mezclaba con nuevas arquitecturas, solares y lotes que hacen las veces de jardines o huertas y un paisaje bastante verde. En este barrio vive la mayoría de las mujeres que hoy conforman Artesanías Choibá. Sus casas son en 
cierta medida prolongaciones del taller de costura donde trabajan diariamente; las mesas, cuartos y espacios comunes están llenos de trabajos en proceso, de herramientas, máquinas, hilos y retazos, pero a su vez son casas hechas, literalmente, con el esfuerzo y el trabajo de las artesanas.

Las mujeres de Choibá se definen como tejedoras, bordadoras y cuidadoras. Por la guerra han llorado hijos, compañeros y familiares, pero también las tierras y los ríos que tuvieron que abandonar ante la ocupación violenta de los actores armados. Llegaron a una ciudad donde la única opción laboral para las mujeres negras rurales era convertirse en "empleadas domésticas", un trabajo donde se reproducen formas de explotación naturalizadas. Actualmente, el grupo está conformado por diez mujeres jóvenes y adultas (y un hombre joven) que además de los oficios textiles se ocupan del cuidado familiar, las labores domésticas y la participación en movilizaciones y actos sociales de resistencia auspiciados por organizaciones étnico-territoriales de la región y la Diócesis de Quibdó. Artesanías Choibá consolidó una forma de trabajo colectivo en la que las labores se distribuyen equitativamente entre la producción en el taller, la venta y administración de la tienda donde ofrecen los productos artesanales, y la enseñanza de técnicas de bordado y tejido a grupos barriales de la ciudad. Úrsula Holzapfel, quien propició la formación del grupo, no ha dejado de enseñar y acompañar el proceso organizativo, formativo y productivo. La producción artesanal se ha extendido hacia la elaboración de muñecas de diversos tamaños, ropa, elementos para la cocina, bolsos y otros accesorios. Una manera de activar la comercialización ha sido participar en ferias artesanales a nivel nacional e impulsar espacios locales, como la Feria Alternativa Justa y Solidaria, que desde el 2004 se realiza en la ciudad de Quibdó junto a otros colectivos regionales de artesanos para promover el consumo local.

Las muñecas negras son los productos característicos de Artesanías Choibá (figura 5), no solo porque son representaciones de ellas mismas como mujeres negras, sino también porque resultan del trabajo grupal. Lo que inicialmente empezó como una herramienta para dar un regalo a sus niños en Navidad y elaborar prendas de vestir para sus familias, pasó a ser un medio para construir nuevas posibilidades de vida en un contexto lleno de precariedades en el que debían empezar de cero después de perderlo todo en sus territorios de origen. 
Figura 5. Muñecas negras expuestas en el punto de venta de Artesanías Choibá

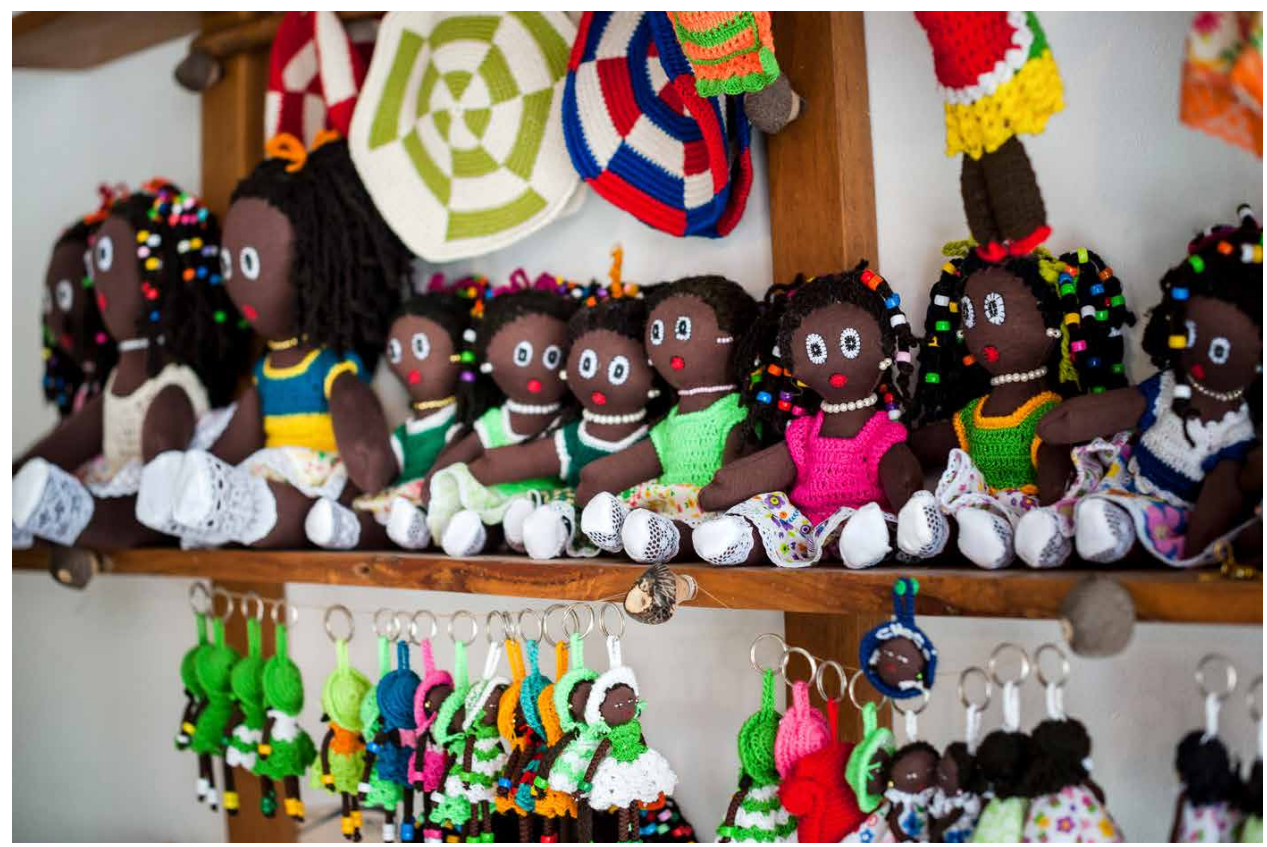

Fuente: fotografía de Federico Ruiz.

Para dar vida a las muñecas, cada integrante se encarga de un paso en la elaboración. Mientras una corta los moldes de los cuerpos, otra los cose y otra los rellena; unas se encargan de vestirlas y, finalmente, algunas las peinan y les dan expresión a sus caras. Como dice Yusy, "la pieza textil que más queremos son las muñecas porque resaltan nuestra belleza y fortaleza”. Son elaboradas en tela acolchada con relleno en fibra siliconada, lana virgen para el cabello y vestidas con pequeñas piezas elaboradas en croché y tela. Se confeccionan en diferentes tamaños y con diferentes estilos: niñas, jovencitas, ancianas, domingueras y bailarinas. Dentro de la línea de muñecas de Artesanías Choibá, también se pueden encontrar indígenas, niños, hombres y pesebres negros.

Luz Romaña fue desplazada de La Grande, poblado anteriormente localizado en la jurisdicción de Riosucio y hoy perteneciente al Carmen del Darién. El Atrato abajo, como suele nombrar su territorio, se mantiene vivo de muchas maneras en la vida cotidiana de Luz. Desde la madera de su casa que aún tiene partes traídas de abajo, el tanque de agua que logró rescatar y recuperar después de ser abaleado por la guerrilla, algunos recuerdos y nostalgias que siempre estarán vivos en su memoria, hasta la indignación por lo que perdió en medio de la guerra y jamás podrá recuperar, entre ello, su compañero. Las manos de esta gran tejedora han bordado, tejido y cosido cada hebra que la guerra destruyó 
en su vida. La dedicación a los oficios textiles le dio el impulso y la fuerza para levantar con sus propias manos y las de sus hijos la casa en la que ha vivido en la ciudad de Quibdó por veinte años.

Después de recibir algunas ayudas humanitarias como mujer desplazada en la ciudad de Quibdó, se dio cuenta de que para reconstruir su vida no era suficiente estar a la espera de esas ayudas, hacer filas y recibir constantemente instrucciones para tramitar en diferentes instancias la demanda de sus propios derechos. Retornar a su tierra no era una alternativa; si bien uno de sus hijos aún vive allá, no se imaginaba su vida volviendo a levantar un negocio sola en un lugar donde había sido asesinado su esposo y las fuerzas de la guerra seguían operando de diferentes maneras. Encontrarse con las mujeres que inicialmente conformaron el grupo Choibá fue la posibilidad de hallar fuerzas para imaginar una vida, también con muchas dificultades y precariedades, pero con el apoyo de otras y otros en los nuevos retos del nuevo lugar. Fue así como empezó a hacer de su oficio de artesana y tejedora no solo un espacio para sanar heridas y dolores personales de la guerra, sino también un proyecto colectivo para reconocer las historias de otras mujeres, crear un modelo colaborativo desde la figura de un fondo común para el reconocimiento económico y convertir esa fuerza de trabajo, tradicionalmente no remunerada o subvalorada, en un aporte económico para el sostenimiento de la familia o la construcción de su propia casa en la ciudad. El taller de costura se convirtió en ese espacio de encuentro, trabajo y cuidado donde no era necesario identificarse como víctima o desplazada para encontrar algún apoyo, para imaginar alguna solución a problemas tan básicos como qué comer el día siguiente o cómo expandir la red comunitaria para el cuidado de los hijos. No se trataba de negar su historia o asumir esa nueva identidad, se trataba de hacer algo creativo con ella. Desde su propia fuerza. Paradójicamente, renunciar a la espera le ha dado más fortaleza para seguir reclamando por sus derechos, para hacer de esa identidad de víctima no una posición subalterna y estigmatizada, sino una entre muchos lugares de enunciación posibles para hacer la vida sin parar de reclamar justicia.

Luz ubica el nacimiento de Choibá en el encuentro con Úrsula Holzapfel, quien trabaja en la Comisión Vida, Justicia y Paz de la Diócesis de Quibdó. Porque, antes que los entes gubernamentales, al Coliseo llegaron organizaciones no gubernamentales y grupos de misioneros para ayudar a los desplazados. Las actividades promovidas por Úrsula en 1998 consistieron en enseñarles a las mujeres a bordar y tejer, creando a su vez encuentros para conversar sobre los dolores y recobrar un poco de la dignidad y esperanza que les habían arrebatado al expulsarlas de sus tierras y ríos. Al año siguiente, once de las ochenta 
mujeres que asistieron a las primeras clases decidieron continuar su formación. Luz recuerda que aprender los oficios manuales no fue sencillo: "Estos dedos se nos ponían huecos y nosotras cogíamos un trapo y nos forrábamos el dedo bien enforraíto y ahí buscábamos esparadrapo pa poder seguir tejiendo, cogiendo la aguja, a mano" (comunicación personal, junio del 2017). Continuar aprendiendo era a su vez la oportunidad de crear otros espacios para encontrarse y construir rutinas juntas en medio de la desatención y negligencia estatal para solucionar su situación como desplazadas. En estos espacios, los recuerdos de los desplazamientos forzados desde Riosucio, el Carmen de Atrato o Carepa, o las muertes de los familiares eran experiencias que ya no se limitaban al testimonio en los espacios institucionales para exigir ayuda humanitaria, sino que se compartían al calor del encuentro entre agujas e hilos (Villamizar 2019).

El sostenimiento del tejido y bordado durante veinte años ha sido una acción fundamental para la reconstrucción de las vidas y los itinerarios cotidianos de las mujeres de Artesanías Choibá después del desplazamiento forzado. Este es un proyecto organizativo y económico que cada día crece también por el trabajo que las mujeres realizan en grupos barriales de Quibdó, donde enseñan a jóvenes y mujeres las técnicas de bordado y tejido para inspirar la creación de nuevas iniciativas artesanales y manuales que permitan reparar los daños de la guerra (Villamizar 2019).

El bordado y la costura son descritos como oficios que muchas aprendieron de sus madres y abuelas. Rubiela recuerda que creció viendo a un padre dejar el oficio de sastre para dedicarse al cultivo de banano, labor que tendría que abandonar en medio de la guerra y el despojo en el Urabá chocoano. La vieja máquina del padre fue el primer objeto que le permitió a Rubiela acercarse y aprender los oficios textiles. Por su parte, Edilma recuerda que, cuando se desplazó de Riosucio, lo primero que empacó fue su máquina de coser. Así, la costura no llega solo después del desplazamiento; en algunos casos, estos oficios y conocimientos ya estaban presentes como formas de cuidar a sus familias, hacer la ropa para los hijos o sumar a la economía del hogar cosiendo para los vecinos. Al llegar a Quibdó y darse el encuentro con otras mujeres, esos oficios se activan con nuevos propósitos, movilizan no solo la vida del hogar y el vecindario, sino que se convierten en una forma de narrar las vivencias, encontrarse con otros, restablecer lazos y sociabilidades rotas, construir nuevas comunidades en el destierro.

Con sus manos, las mujeres de Artesanías Choibá narran su camino y su lucha como un grupo de resistencia capaz de responder pacíficamente a las consecuencias de la guerra. Desde la esfera cotidiana del trabajo del tejido y las artesanías, disputan los lugares socialmente asignados a las “mujeres negras rurales” 
en la ciudad de Quibdó, donde se han sentido discriminadas por ser mujeres, negras, campesinas y desplazadas. Cada tejido, muñeca o artesanía hace eco de la fuerza colectiva que las ha mantenido resistiendo, como el árbol de choibá. En el encuentro cotidiano de su taller y punto de venta en Quibdó, han logrado configurar una iniciativa de comercio justo que consiste en el trabajo cooperativo de distribución de labores y ganancias sin intermediarios, una estrategia en la que todas las fases de producción se basan en la construcción de redes de solidaridad. Así, la obtención de materiales que no son producidos en Quibdó, sino que se deben solicitar a ciudades como Bogotá o Medellín, se hace por medio de contactos colaboradores para el envío; de igual manera, las decisiones sobre qué fabricar dependen de los pedidos y encargos que directamente recibe el grupo. Esta dinámica de producción se diferencia del trabajo artesanal al servicio de modelos estandarizados y producción masiva de objetos con "identidad regional” que, al entrar en la lógica de los intermediarios, terminan subestimando los valores y el trabajo de producción original de las artesanas y artesanos. En cada muñeca o pieza textil que elaboran mantienen viva la pregunta por su ser mujer negra desplazada que no retorna a su tierra y lo que eso implica en una ciudad como Quibdó; tal como describen en su proyecto productivo "Hecho a mano por mujeres que resisten”, las integrantes de Artesanías Choibá visibilizan y reivindican su trayectoria no solo como víctimas, sino como artesanas.

\section{Guayacán}

Algunas de las mujeres que hoy integran Guayacán recuerdan que este grupo surgió de una comunidad eclesial de base (CEB), en el pueblo de Bellavista. Estas agrupaciones fueron impulsadas en los años 1980 en el Atrato por misioneros y misioneras, y en el pueblo de Bojayá fueron las Hermanas Agustinas Misioneras y el padre Jorge Luis Mazo $^{9}$ quienes, a finales de los años 1990, animaron a las mujeres a conformar uno de estos grupos. Leer la Biblia y crear oraciones en el contexto sociopolítico que se vivía entonces en el Atrato, donde la avanzada de los paramilitares amenazaba la permanencia de las comunidades en el río, fueron actividades que necesariamente reunieron a las mujeres en torno a la pregunta de cómo sobrevivir y resistir en medio de los actores armados, especialmente frente a la avanzada paramilitar y la inminente confrontación anunciada con la guerrilla de las FARC-EP.

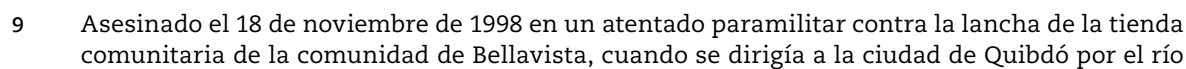
Atrato. 
El grupo de oración tomó tanta fuerza en esta época que llegaron a participar más de cincuenta mujeres que, alrededor de la espiritualidad y el deseo de transformar el miedo y la zozobra, crearon proyectos productivos para tener alternativas de supervivencia. Fue así como la CEB se transformó en el grupo Guayacán, un colectivo de mujeres que, además de leer la Biblia y reflexionar sobre las realidades de sus comunidades, comenzó a bordar y a construir la primera panadería comunitaria de Bellavista. El conocimiento sobre el bordado se concretó con la idea inicial de elaborar camisetas con elementos del paisaje local para la venta, pero ese conocimiento y los productos fueron transformándose por los efectos de la guerra en la vida del pueblo y el grupo (Villamizar 2019), como veremos más adelante.

Las acciones cotidianas impulsadas por el grupo comenzaron a ser centrales para el sostenimiento de la vida en medio de un contexto sociopolítico adverso. El pan, por ejemplo, se convirtió en un elemento fundamental de la dieta a finales de los años 1990, momento en que los bloqueos impuestos por los paramilitares afectaron la movilidad por el territorio, restringieron la visita cotidiana a las parcelas y afectaron la seguridad alimentaria de las comunidades rurales que no podían tener acceso permanente a sus cultivos de plátano, principal alimento de la dieta atrateña. Por su parte, el espacio de bordado como oficio feminizado y localizado en la esfera de lo doméstico (Pérez-Bustos 2016) no generaba sospecha entre los actores armados y no se asociaba con la posibilidad del encuentro político para la resistencia.

Algunas mujeres del grupo consideran que después de la masacre del 2 de mayo del 2002, en la que varias de sus integrantes perdieron la vida, el proyecto colectivo se transformó radicalmente; no volvieron a ser las mismas. En ese nuevo escenario de victimización colectiva y horror, los oficios y conocimientos asociados a la espiritualidad afroatrateña, como el canto, el cuidado de santos y muertos, emergieron como ejes importantes del grupo Guayacán (Quiceno 2016). Por ejemplo, su trabajo espiritual en torno al cuidado del cristo que estaba dentro de la iglesia aquel día - y que, al igual que el pueblo, quedó sin pies ni manos pero resistió a los ataques- se convirtió en una tarea que continúa vigente. A esta figura santa los habitantes del pueblo le dieron el nombre de Cristo Mutilado de Bojayá; a partir de él han creado un repertorio de actividades espirituales como oraciones y novenas para pedir protección, pero también para cohesionar a la comunidad alrededor de un símbolo colectivo y no permitir el olvido de quienes murieron ese día y las responsabilidades de los actores armados.

La iglesia que fue reconstruida es considerada por los bojayaseños como un lugar sagrado porque conserva la fuerza de los caídos en la masacre. Por eso, 
desde el 2011 las mujeres del grupo Guayacán, con el apoyo de los equipos misioneros, emprendieron la gestión para declarar santuario a la iglesia del pueblo viejo. Las ruinas del pueblo viejo no son lo único que caracteriza el lugar; la iglesia reconstruida, cuidada y decorada cada 2 de mayo representa la memoria de ese acontecimiento atroz que marcó las vidas de los bojayaseños y de las mujeres de este colectivo, pero también la memoria de la vida misma, el lugar donde está enterrado el ombligo de sus hijos ${ }^{10}$.

Estos trabajos alrededor de la memoria se articulan al oficio del bordado. Sus conocimientos textiles suspendidos para atender nuevas demandas en el contexto de guerra comienzan a aparecer como caminos para narrar lo sucedido, hacer homenaje a sus muertos y dedicar tiempo a su memoria. El bordado del primer telón de la conmemoración de la masacre de Bojayá, con el cual inició este artículo, fue un acto ritual que ayudó a sobrellevar el dolor y mitigar la deuda con sus muertos, que solo pudo cerrarse, parcialmente, en noviembre del 2019 cuando concluyó la entrega de los restos de sus familiares y la realización de un entierro final.

Retomar el bordado como oficio e imaginar otros oficios manuales y artesanales continúan siendo hoy una apuesta de quienes integran Guayacán. Las múltiples intervenciones del pueblo de Bellavista después de la masacre han demandado la participación de las mujeres, en muchos casos, sin que se reconozcan sus conocimientos, afinidades y modos de hacer propios. La principal intervención que reconfiguró radicalmente sus vidas fue la reubicación de su pueblo en el 2007. Esto ha implicado que las mujeres de la agrupación se sumen a dinámicas que, con la intención de reparar y aportar a la reconstrucción de la vida, en muchos casos implicaron el debilitamiento del grupo. Criar pollos, cultivar peces, sembrar plátano, mantener vivo el lugar de memoria, involucrarse en un plan de reparación colectiva, cocinar en eventos comunitarios, acompañar y cuidar a las familias de las víctimas en el proceso de exhumación son algunas de las actividades relacionadas con su oficio textil y artesanal. Esta agrupación se sostiene mediante el trabajo de ocho mujeres que conforman el colectivo de base y de otras cuya participación fluctúa en las reuniones y actividades organizativas. Ha tenido varios cambios en su composición y, aunque se han presentado crisis en el relevo generacional, el grupo ha creado estrategias como la de invitar

10 El entierro del ombligo es un ritual de curación del ombligo del recién nacido con sustancias previamente seleccionadas por los padres y la partera para que la persona adquiera la fuerza del vegetal o animal con el que fue ombligado, así como una forma de conexión y arraigo al territorio (Arocha 2009). 
a mujeres indígenas y formar el grupo Semillitas de Guayacán con los niños y niñas del pueblo para enseñar sus oficios y que estos no se olviden.

El oficio textil en la experiencia del grupo Guayacán ha estado atravesado por las dinámicas de la guerra y por las apuestas de reconstrucción de su pueblo. Si bien es una actividad que las congrega creando espacios para la resistencia en medio de las presiones de los actores armados, también se vio afectada (como la cotidianidad en su conjunto) después de la masacre, el desplazamiento, el retorno y la reubicación. Perder mujeres importantes para el colecivo y atender nuevas demandas de actores externos para participar en la reconstrucción de su pueblo se hizo dándole otro lugar al bordado.

Este oficio aparece de nuevo como una posibilidad de hacer memoria, de recordar, cuidar y recuperar el nombre de sus muertos, dedicando tiempo, volviendo sobre sus vidas y dándole un lugar desde la materialidad del bordado y la tela que se plasma en el gran telón. En el 2016 se hizo un segundo telón de las víctimas del 2 de mayo para proteger la primera versión, que en sus diecisiete años de historia ha viajado a diferentes exposiciones, espacios de activismo e incluso a otros países, como Estados Unidos. Los viajes del telón son también viajes de las mujeres que van dando testimonio de su historia. Hoy Guayacán continúa la tarea cotidiana de reconstruir lazos comunitarios, sanar heridas que siguen vivas, acompañar y atender nuevas amenazas y víctimas en un conflicto que no para. Con el acompañamiento de proyectos de extensión de las universidades de Antioquia e Icesi de Cali, la continuidad del trabajo de la Comisión Vida, Justicia y Paz de la Diócesis de Quibdó, la Unidad de Atención para las Víctimas, así como desde espacios de trabajo colectivo como el Comité por los Derechos de las Víctimas de Bojayá, el grupo sigue participando con el bordado, la costura y otros oficios, como la cocina, la panadería y el acompañamiento espiritual. Entre todos esos oficios los que se resisten a encuadrarse exclusivamente en los eventos coyunturales que convocan a las víctimas son el bordado y la costura. Los hilos, las telas y los materiales que llegan, por diversas donaciones o por su propia gestión, tienen el poder de reunirlas para conversar cotidianamente. Las pocas cosas que se hacen como iniciativa productiva se venden cada año en la Feria Alternativa Justa y Solidaria que organizan con apoyo del grupo Choibá y otros grupos de artesanas en la ciudad de Quibdó. A diferencia de Choibá, Guayacán no ha logrado hacer de su labor textil un proyecto productivo que les dé autonomía económica; sin embargo, es este oficio el que mantiene vivo al grupo y las convoca como mujeres. 


\section{Oficios, conocimientos y espacios}

Durante uno de los encuentros realizados en Quibdó con los colectivos de artesanas en el marco del proyecto "Remendar lo nuevo", se les pidió que hablaran de una pieza textil que representara para ellas la reconciliación y la reparación de sus mundos afectados por el conflicto armado. El colectivo de Artesanías Choibá sorprendió a quienes estábamos en la sala cuando salieron todas al centro del espacio vestidas con faldas tejidas por ellas mismas en la técnica de croché, la misma con la que tejen los vestidos de las muñecas negras que comercializan en su punto de venta detrás de la catedral de Quibdó. Más que representar un paisaje, un deseo o proponer una imagen, fueron sus cuerpos vestidos con su propio trabajo lo que les permitió hablar de apuestas de reconciliación y reparación. La ropa, el vestido, la costura y esas faldas hechas con todo el cuidado para sí mismas evidencian reconfiguraciones en las prácticas de cuidado normalmente asignadas a las mujeres. Se muestra cómo en el trabajo colectivo de un taller de costura, en las discusiones públicas de estas artesanas sobre la vida cotidiana, las necesidades y posibilidades que les ofrece la ciudad, se renuevan las propuestas de cuidarse, consentirse, embellecer sus cuerpos y sus espacios como camino para la dignificación de sus vidas. Al narrar el significado de las faldas todas hablaron del sentido que tienen en sus vidas el tejido y el aprendizaje que han recibido de sus maestras y compañeras en el grupo Choibá; también, de que hacer parte de este espacio les permitió expandir sus miradas y proyectar sus vidas a otros sueños sin quedarse atrapadas en el dolor de la guerra. Volver a estudiar, enseñarles a otras mujeres en sus barrios, formarse en redes y colectivos de mujeres son algunas de esas acciones que se proyectan desde el trabajo textil. Como lo sintetiza otra de las integrantes, el encuentro con el tejido después del desplazamiento forzado fue "aprender en medio de tanto menosprecio".

El hacer textil y artesanal de Guayacán y Choibá, los materiales, instrumentos y lugares que lo hacen posible crean en las experiencias de las mujeres una red de relaciones que han activado en los últimos veinte años soluciones, alternativas y caminos para la recomposición de sus vidas. Hablar de oficios reparadores y espacios de vida implica por lo tanto una comprensión de la interdependencia de ambas dimensiones; entender cómo las prácticas, haceres y técnicas permiten el encuentro, la reunión, la creación de un colectivo de mujeres, que a su vez va configurando una serie de espacios físicos y sociales: talleres, casas, salones, puntos de venta, donde la vida intenta escapar a la guerra. Mantener vivos esos espacios, hacer de ellos una posibilidad de crear, pasa por conservar vivos los oficios que unen a las mujeres en el hacer colectivo y activar 
los conocimientos asociados. No se trata solo de una reunión, de una suma de personas alrededor de un proyecto de "resistencia" o "lucha" predeterminado. Se trata de una lucha que se crea cotidianamente en tejer, bordar, hacer muñecas y acompañar estos oficios de experiencias vitales como cocinar o cuidar de los hijos y parientes.

El conflicto armado se infiltra en la vida en diversas escalas: cuerpos, emociones, territorios, subsistencia y organización social. Por lo tanto, es necesario ubicar las vidas de estas mujeres en medio de las confrontaciones y amenazas que la exclusión, los conflictos por la tierra y el conflicto armado han protagonizado en sus territorios, máxime cuando han sido estos fenómenos los que han impactado y redireccionado los caminos y trayectorias que ellas y sus colectivos han seguido durante las últimas dos décadas.

Hacer visibles los modos como se afecta la vida de las mujeres en medio de la guerra y, de ese modo, la vida de sus pueblos implica reconocer el papel histórico que han desempeñado en la protección y lucha por derechos colectivos, por formas de bienestar dentro de la comunidad y por mantener activas las conexiones y modos de existir con y desde sus propios territorios (Camacho 2004; Mina 2012; Vergara-Figueroa 2018). Es hacer visibles las herramientas, los conocimientos y las estrategias a los cuales han apelado para sostener esas luchas y vidas, y entender cómo ellas promueven, desde sus cotidianidades, estrategias para rehabitar que reconfiguran las fronteras entre lo público y lo privado, al situar experiencias personales e individuales en espacios y proyectos colectivos que crean redes de trabajo y acompañamiento. Esta articulación singular que las mujeres atrateñas crean entre espacios, oficios y conocimientos evidencia un proceso potente de reconfiguración de sus subjetividades que trasciende la noción de víctimas. Reconocerse como artesanas y hacer de su oficio textil una práctica que reordena el ritmo cotidiano, así como los lazos comunitarios y solidarios entre mujeres, ofrecen otros marcos subjetivos que no se limitan a la representación como víctimas o a la espera de la reparación que, en cuanto tales, les debe brindar el Estado. En este sentido, estas dos experiencias en las que las prácticas textiles se activan para articular luchas y apuestas de las mujeres en el Atrato nos muestran cómo la reparación para ellas no se asocia exclusivamente a las políticas de atención y reconocimiento de las víctimas en Colombia, sino que aparece, sobre todo, como un trabajo cotidiano que involucra diversos oficios, relaciones y materialidades partícipes en el sostenimiento de la vida en medio de la precariedad.

Estos oficios han ganado un importante despliegue en los colectivos de mujeres víctimas del conflicto armado en Colombia, han sido caracterizados como espacios de gestión emocional (Bello y Aranguren 2020), estrategias de cuidado 
y promoción de la salud mental (Arias 2013), textiles testimoniales para documentar las experiencias del conflicto armado (González 2019), y también como prácticas estético-artísticas de memoria y construcción de paz (Belalcázar y Molina 2017). Vemos, en suma, que los oficios, las materialidades, los espacios y los conocimientos se conjugan en la dimensión íntima y pública de la vida cotidiana con proyectos de transformación y emancipación colectiva. Son oficios que además se enmarcan en una red de trabajos del cuidado (Molinier y Arango 2011; Pérez-Bustos et al. 2018), donde hacer la ropa para sus hijos, tejerse un vestido como regalo para sí misma, hacer de sus compañeras artesanas una red de apoyo y solidaridad, ganar el sustento bordando o construir su casa con el trabajo en el taller de costura son todos hilos que van permitiendo concretar, desde relaciones y materialidades del día a día, una reparación o recuperación que no llega desde las políticas y programas del Estado.

Dos pancartas grandes ubicadas a cada lado de la entrada al convento con ilustraciones de peces y la frase “Todos somos guardianes del río Atrato” recibían a los visitantes de la decimocuarta versión de la Feria Alternativa Justa y Solidaria, realizada en Quibdó en septiembre del 2018. Uno de los objetivos en la realización anual de la feria es contribuir desde este espacio a la reflexión y el debate de algún tema coyuntural de la región o el país que afecte a las comunidades. En esta edición, los grupos de artesanas y artesanos participantes propusieron como temática la protección y el cuidado del río Atrato declarado como sujeto de derechos mediante la Sentencia T-622 del 2016 por la Corte Constitucional. Las mujeres de Artesanías Choibá y Guayacán contribuyeron activamente diseñando la decoración y creando nuevos productos para ambientar sus puestos de venta. En las reuniones para la planeación de la feria se propuso realizar, para la decoración de los corredores, los puestos de venta y el patio central, unos peces en telas de colores con diversos diseños y tamaños. Estos fueron cosidos por las mujeres de Artesanías Choibá y rellenados por todos los grupos con plástico reciclado, para evocar metafóricamente cómo los peces que crecían en el río estaban siendo envenenados por la contaminación de la minería mecanizada y el mercurio utilizado en esta práctica. Por su parte, las mujeres de Artesanías Guayacán llevaron para su puesto nuevos productos, como unos bolsos cosidos y pintados donde se podía leer la frase "Atrato es, Atrato soy, Atrato somos y debemos seguir siendo”, en la que proyectaban su identificación con el río, su labor de cuidado que consiste en entenderse como parte de él y comprender que, si su circuito vital no está bien, no lo están las comunidades. De esta manera, ambos colectivos, con su hacer textil y artesanal, se suman a las discusiones y luchas regionales, proponiendo otras formas creativas de socializar y promover debates más allá 
de los circuitos de las organizaciones. Así, la restauración y el cuidado del río también se impulsan en las calles con los bolsos, las camisetas y los suvenires elaborados por estas mujeres.

Transgredir los lugares tradicionalmente asignados a las mujeres "negras, campesinas y desplazadas", como se identifican las pertenecientes a estos colectivos, para crear nuevos espacios de acción política, reconstrucción, reparación $\mathrm{y}$, sobre todo, el cuidado de lo que la guerra ha dañado, evidencia formas de "insurgencias políticas y epistémicas" (Lozano 2016, 14) con las que se contesta al proyecto de muerte que encarna el conflicto armado en la región del Atrato. Estos oficios reparadores asociados a los haceres textiles de las mujeres de Choibá y Guayacán nos enseñan cómo se activan y conectan conocimientos que constituyen saberes para la vida (Lozano 2016, 15). Que estos oficios permitan denunciar y documentar las experiencias vividas en la guerra, reafirmar una identidad, al tiempo que reconfigurar formas de sociabilidad, muestra su dimensión política. Como lo evidencian las trayectorias de más de veinte años de estos dos grupos, su trabajo y organización les ha permitido recuperar un sentido de lo colectivo tanto alrededor de las experiencias dolorosas vividas en tanto víctimas del conflicto, como en su autorreconocimiento como mujeres negras. Artes de hacer cotidianas que, articuladas a conocimientos que se desarrollaban antes en la intimidad de sus casas o se desconocían, hoy logran tejer apuestas para organizarse y crear. Los proyectos de artesanías se convierten, de esta manera, en mucho más que un taller de trabajo manual; son colectivos que desde sus bordados, muñecas, telones y tejidos configuran perspectivas sobre sus vidas y su región. Una fuerza política localizada en la creatividad y no en la confrontación (Certeau 2000).

A partir de las experiencias compartidas con estas artesanas entendemos la reparación no como una acción concluida, sino como un proceso siempre en tensión con la continuidad de la guerra en los territorios, así como con la necesidad de seguir reclamando la garantía de los derechos de las víctimas, de lo cual el Estado es el principal responsable. Los oficios artesanales de Guayacán y Choibá, sus productos y los espacios donde estos se desarrollan evidencian una lucha cotidiana por el reconocimiento que está en diálogo constante con las políticas y discursos cambiantes sobre las víctimas en Colombia.

Los oficios reparadores pueden ser entendidos, entonces, como el repertorio de actividades creativas cotidianas que ponen en escena una lucha por el reconocimiento de las víctimas como sujetos políticos con proyectos activos para transformar sus vidas. La vitalidad de esos oficios es sostenida en interdependencia con espacios y conocimientos que aportan y a su vez transforman los lenguajes y las acciones políticas por la defensa del territorio, el río, el cuerpo, la 
vida, la memoria y la autonomía. Las apuestas impulsadas desde los espacios de trabajo de Guayacán y Choibá ponen en escena relaciones entre subsistencia, búsqueda de autonomía económica, gestión de las emociones (Bello y Aranguren 2020), reconocimiento de identidades colectivas como mujeres negras y víctimas del conflicto armado, así como la posibilidad de imaginar y representar su territorio desde el bordado y el tejido.

\section{Referencias}

Agudelo, Carlos. 2001. “El Pacífico colombiano: de 'remanso de paz’ a escenario estratégico del conflicto armado”. Cuadernos de Desarrollo Rural 46: 7-37.

Arias, Beatriz. 2013. "Violencia, resistencia, subjetividad: destejer y tejer la salud mental. Estudio de caso municipio de San Francisco, oriente antioqueño, Colombia 2011-2012”. Tesis doctoral, Departamento de Salud Comunitaria, Universidad Nacional de Lanus, Buenos Aires.

Arocha Rodríguez, Jaime. 2009. “Homobiósfera en el Afropacífico”. Revista de Estudios Sociales 32: 86-97. https://journals.openedition.org/revestudsoc/16539

Balduino de Melo, Paula. 2015. "Matronas afropacíficas: fluxos, territórios e violências. Gênero, etnia e raça na Colômbia e no Ecuador”. Tesis del Programa de Pósgraduação em Antropologia Social, Universidade de Brasilia, Brasilia.

Barber, Kattalin. 2019. "Silvia Rivera Cusicanqui: Tenemos que producir pensamiento a partir de lo cotidiano”. El Salto, 17 de febrero. https://www.elsaltodiario.com/feminismo-poscolonial/silvia-rivera-cusicanqui-producir-pensamiento-cotidiano-pensamiento-indigena

Belalcázar John y Nelson Molina. 2017. "Los tejidos de las mujeres de Mampuján: prácticas estético-artísticas de memoria situada en el marco del conflicto armado colombiano”. Andamios 14 (34):59-85.http://www.scielo.org.mx/scielo.php?script=sci_abstract\&pid=S187000632017000200059\&lng=es\&nrm=iso

Bello, Andrea Carolina y Juan Pablo Aranguren. 2020. "Voces de hilo y aguja: construcciones de sentido y gestión emocional por medio de prácticas textiles en el conflicto armado colombiano". H-ART. Revista de Historia, Teoría y Crítica de Arte 6: 181-204. https://doi. org/10.25025/hart06.2020.10

Burgos, Roberto, ed. 2010. Rutas de libertad. 500 años de travesía. Bogotá: Ministerio de Cultura; Pontificia Universidad Javeriana.

Camacho, Juana. 2004. "Silencios elocuentes, voces emergentes: reseña bibliográfica de los estudios sobre la mujer afrocolombiana”. En Panorámica afrocolombiana. Estudios sociales del Pacífico, editado por Mauricio Pardo, Claudia Mosquera y María Clemencia Ramírez, 167-208. Bogotá: ICANH. 
Certeau, Michel de. (1990) 2000. La invención de lo cotidiano. Vol. 1: Artes de hacer. Ciudad de México: Universidad Iberoamericana; Instituto Tecnológico y de Estudios Superiores de Occidente.

“Con capítulo especial para Chocó arranca cese del fuego con el ELN". 2017. Verdadabierta.com, 2 de octubre. https://verdadabierta.com/con-capitulo-especial-para-choco-arranca-cese-del-fuego-con-el-eln

Congreso de Colombia. 1993. Ley 70 de 1993 "Por la cual se desarrolla el artículo transitorio 55 de la Constitución Política”.

Corte Constitucional de la República de Colombia. 2016. Sentencia T-622 del 2016.

Defensoría Delegada para la Prevención de Riesgos de Violaciones a los Derechos Humanos y DIH (Derecho Internacional Humanitario). 2016. Problemática humanitaria en la región Pacífica colombiana-subregión Chocó. Bogotá: Defensoría del Pueblo de Colombia.

Defensoría del Pueblo. 2018. Alerta Temprana 011-18, 24 de enero.

Estalella, Adolfo y Tomás Sánchez Criado. 2018. "Introduction: Experimental Collaborations”. En Experimental Collaborations. Ethnography through Fieldwork Devices, editado por Adolfo Estalella y Tomás Sánchez Criado, 1-30. Oxford; Nueva York: Berghahn.

Gobierno de la República de Colombia de Juan Manuel Santos y Fuerzas Armadas Revolucionarias de Colombia-Ejército del Pueblo. 2016. "Acuerdo Final para la Terminación del Conflicto y la Construcción de una Paz Estable y Duradera”. Consultado el 20 de febrero del 2020. http://www.altocomisionadoparalapaz.gov.co/procesos-y-conversaciones/ Documentos\%20compartidos/24-11-2016NuevoAcuerdoFinal.pdf

González Arango, Isabel. 2019. "Repositorio digital para la documentación de textiles testimoniales del conflicto armado en Colombia”. Tesis de maestría, Escuela Interamericana de Bibliotecología, Universidad de Antioquia, Medellín.

Holzapfel, Úrsula y Ulrich Kollwitz. 2014.40 años de conflicto en el Alto y Medio Atrato. Un análisis con base en 929 casos de personas asesinadas o desaparecidas. Medellín: Nuevo Milenio.

Lozano, Betty Ruth. 2014. "El feminismo no puede ser uno porque las mujeres somos diversas. Aportes a un feminismo negro decolonial desde la experiencia de las mujeres negras del Pacífico colombiano". En Tejiendo de otro modo. Feminismo, epistemología y apuestas descoloniales en Abya Yala, editado por Yuderkis Espinosa, Diana Gómez Correal y Karina Ochoa Muñoz, 335-352. Popayán: Universidad del Cauca.

-. 2016. "Tejiendo con retazos de memorias insurgencias epistémicas de mujeres negras/ afrocolombianas. Aportes a un feminismo negro decolonial”. Tesis doctoral en Estudios Culturales Latinoamericanos, Área de Estudios Sociales y Globales, Universidad Andina Simón Bolívar, sede Ecuador.

"El mapa de los líderes sociales asesinados en Colombia”. 2018. El Tiempo. https://www. eltiempo.com/colombia/otras-ciudades/el-mapa-de-los-lideres-sociales-asesinados-encolombia-184408

Mina Rojas, Charo. 2012. "Derrotar la invisibilidad. Un reto para las mujeres afrodescendientes en Colombia. El panorama de la violencia y la violación de los derechos humanos contra las mujeres afrodescendientes en Colombia, en el marco de los derechos colectivos. 
Proyecto Mujeres Afrodescendientes Defensoras de Derechos Humanos (PCN)”. http:// www.afrocolombians.org/pdfs/DerrotarlaInvisibilidad.pdf

Molinier, Pascale y Luz Gabriela Arango, comps. 2011. El trabajo y la ética del cuidado. Medellín: Universidad Nacional de Colombia; La Carreta Editores.

Pérez-Bustos, Tania. 2016. "El tejido como conocimiento, el conocimiento como tejido: reflexiones feministas en torno a la agencia de las materialidades". Revista Colombiana de Sociología 39 (2): 163-182. https://doi.org/10.15446/rcs.v39n2.58970

Pérez-Bustos, Tania, Luz Gabriela Arango, Javier A. Pineda y Adira Amaya Urquijo. 2018. Género y cuidado. Teorías, escenarios y políticas. Bogotá: Centro Interdisciplinario de Estudios sobre Desarrollo (Cider).

Quiceno, Natalia. 2016. Vivir sabroso. Luchas y movimientos afroatrateños en Bojayá Chocó. Bogotá: Universidad del Rosario.

Quiceno, Natalia, María Ochoa y Adriana Villamizar. 2017. "La política del canto y el poder de las alabaoras de Pogue (Bojayá, Chocó)”. Estudios Políticos 51: 175-195. http://www.scie lo.org.co/scielo.php?pid=S0121-51672017000200175\&script=sci_abstract\&tlng=es

Red Nacional de Información. 2018. "Registro Único de Víctimas”. Consultado el $1 .^{\circ}$ de octubre del 2018. https://www.unidadvictimas.gov.co/es/registro-unico-de-victimas-ruv/37394

Rivera Cusicanqui, Silvia. 2018. Un mundo Ch'ixi es posible. Ensayos desde un presente en crisis. Buenos Aires: Tinta Limón.

Romero, Mauricio. 2010. "Desprotección, estigmatización y despojo: un Estado regional depredador en el norte del departamento del Chocó”. En Desplazamiento en Colombia. Prevenir, asistir, transformar. Cooperación internacional e iniciativas locales, compilado por Cristina Churruca y Donny Meertens, 249-277. Medellín: La Carreta.

Vergara-Figueroa, Aurora. 2018. Afrodescendant Resistance to Deracination in Colombia. Massacre at Bellavista-Bojayá-Chocó. Cham: Palgrave Macmillan.

Vergara-Figueroa, Aurora y Katherine Arboleda. 2014. "Feminismo afrodiaspórico. Una agenda emergente del feminismo negro en Colombia”. Universitas Humanística 78: 109-134. http://revistas.javeriana.edu.co/index.php/univhumanistica/article/view/6404/8195

Villamizar, Adriana. 2019. “Del ‘derecho a la reparación’ a la reconstrucción de la vida: trayectorias de los grupos de mujeres Artesanías Guayacán y Choibá frente a la reparación en el Medio Atrato chocoano”. Monografía de Sociología, Facultad de Ciencias Sociales y Humanas, Universidad de Antioquia, Medellín. 